\title{
Couriers' safety and health risks before and during the COVID-19 pandemic
}

\author{
Laliv Egozi $^{1} \mathbb{D} \cdot$ Nitzan Reiss-Hevlin $^{1} \cdot$ Rana Dallasheh $^{1} \cdot$ Asher Pardo $^{1}$
}

Received: 13 April 2021 / Accepted: 21 June 2021 / Published online: 17 October 2021

(c) The Author(s), under exclusive licence to Springer-Verlag GmbH Germany, part of Springer Nature 2021

\begin{abstract}
Objectives This study aimed to examine the safety and health hazards of motorized couriers and investigate working conditions and driving behavior possibly associated with involvement in road accidents while driving motorcycles or cars. In light of the outbreak of COVID-19, the study was aimed to explore factors that affect the couriers' behaviors related to decreasing the risk of contracting an infectious disease.

Methods A sample of 237 Israeli couriers, about half who drove a two-wheeled vehicles and the others who drove cars, answered an online survey questionnaire. The questionnaire examined organizational, occupational, and personal factors regarding their working conditions, behavior on the road, musculoskeletal disorders, road accidents, and perceptions of and compliance with regulations regarding COVID-19. The data were analyzed by multiple regression in SPSS 25, structural equation modeling and mediation tests in R 3.6.2.

Results According to the couriers' self-report, $37 \%$ reported musculoskeletal pains at least once a day, $13 \%$ of them were involved in work-related road accidents and $10 \%$ reported feeling stress at least once a week. More than $60 \%$ of the couriers reported increased stress due to the COVID-19 pandemic. Weekly working hours, shift duration and stress were related to involvement in accidents through the mediation of driving while feeling unwell. Reported stress and the weight of parcels were related to musculoskeletal pains.

Conclusions The findings suggest that stress and attributes of work overloads experienced by couriers are associated with reduced safety and impaired health. Organizational, individual, and societal factors were correlated with the degree to which the couriers adhered to COVID-19 regulations. The increased prevalence of new modes of employment relationships in the field highlights the importance of research on employment conditions and safety and health aspects related to this occupation.
\end{abstract}

Keywords Couriers $\cdot$ Accident $\cdot$ Safety $\cdot$ Health $\cdot$ Musculoskeletal $\cdot$ COVID-19

\section{Introduction}

A couriers' job is flexible hence, the working conditions are varied and depend on the mode of employment, type of delivery, and type of employing organization. In recent years, this new concept of working based on an online "platform" through companies such as Wolt has entered the field of deliveries. In this form, the courier is self-employed and depends on a marketing platform for work, without employer-employee relations. These conditions reduce the

Laliv Egozi

lalive@osh.org.il

1 Israeli Institute for Occupational Safety and Hygiene, Tel Aviv, Israel employer's responsibility for social benefits or maintenance and insurance of the delivery vehicle (Jacobsen Cesko 2020).

Most of the work of couriers takes place outdoors, where they are exposed to various environmental conditions such as weather, pollution and the risk of accidents. (Canadian Center for Occupational Health and Safety 2021). The demand for fast deliveries and payment per delivery in some modes of employment put extra stress on couriers that increases the risk of unsafe behaviors and involvement in accidents (Elfering et al. 2015; Nahrgang et al. 2011; Petitta et al. 2019).

In addition to extra financial stress and an increase in couriers' workloads (Palmer 2020), the COVID-19 pandemic raised the risk of infection. The virus is transmitted when an infected person comes in close contact with another person. Due to their many customers, suppliers, and coworkers, 
couriers are at higher risk of transmission (World Health Organization 2021).

The combination of potential safety and health risks with varied terms of employment puts this population at risk of inadequate health and safety at work in general and during the COVID-19 pandemic in particular. This study was initiated to examine the working conditions of couriers in Israel, their safety behaviors and the correlations between them and the risk of accidents and health problems.

\section{Safety behavior and risk of physical injury and accidents}

Couriers are at increased risk of involvement in road accidents because they spend considerable time driving. However, few studies have been published on this topic. A South Korean study analyzed 1,317 injury reports involving motorcyclist couriers, including 293 teenagers (22.2\%). Most accidents $(87.1 \%)$ were found to result from violations of traffic laws such as speeding, substance use, crossing an intersection on a red light, or driving in opposing traffic lanes. There were more reports of law violations at night and more accidents among teenage couriers $(79.5 \%$ of all accidents relative to $22 \%$ of the sample) (Byun et al. 2020).

In addition to the risk of being involved in road accidents, couriers experience working conditions that may result in slip-and-fall accidents. Outdoor work exposes couriers to various weather conditions (rain, snow, etc.), and obstacles. Limited level of safety management and employee oversight makes it difficult to implement protective and preventive measures. Forty English postmen were interviewed within a few days after involvement in an accident. Falling accounted for $85 \%$ of all accidents and resulted in the loss of about $35 \%$ of working days. The mail couriers reported unsafe behaviors such as skipping stairs, mainly due to their need to save time and shorten the work day. A quarter of respondents had worked more than $9 \mathrm{~h}$ in each of the two days prior to the accident (Haslam and Bentley 1999). Long shifts induce fatigue that increases the risk of involvement in accidents (Fang et al. 2015). Moreover, the postmen reported time pressure. Stressed employees are at increased risk of negligence and involvement in work accidents due to the demand for rapid performance, distractions that accompany high workloads, and to reduced adherence to work procedures in an effort to shorten work processes (Elfering et al. 2015; Nahrgang et al. 2011; Petitta et al. 2019). The economic situation and terms of employment may drive couriers to engage in unsafe and unhealthy behaviors due to time pressure and financial stress that pose extra health and safety risks to them and their environment. Reports of an increase in deaths among couriers in South Korea due to extreme overload of work (Sang-Hun 2020) are one example.

Based on the reviewed literature we hypothesize that:
H1: Working conditions are related to accidents.

H1a: Workload is negatively related to safety behavior through the mediation of stress. As such, workload is positively related to stress and stress is negatively related to safety behavior.

H1b: Safety behavior is negatively related to involvement in road accidents

\section{Ergonomic risks and musculoskeletal pain}

Daily delivery work exposes couriers to ergonomic risks that are related to work requirements and may harm their health. Couriers can develop musculoskeletal disorders due to lifting and carrying parcels and from long driving hours. A study conducted in Malaysia found that about $70 \%$ of the couriers complained of musculoskeletal pain, most commonly lower back pain (60.8\%). Lower level of education and working as a courier for more than 18 months were related to more health problems (bin Abu Hanifah 2015). A similar correlation between musculoskeletal problems and years of exposure was found for many occupations (Ervasti et al. 2019). Whether due to physical overload or other causes, the relationship between stress and musculoskeletal pain has been found in many studies, but the nature of the relationship and whether stress increases musculoskeletal pain - for example, due to muscle contraction - or musculoskeletal pain increases stress due to pain system stimulation has not yet been determined (La Porta and Tappe-Theodor 2020).

We hypothesized the following.

$\mathrm{H} 2$ : Workload and stress of couriers are positively related to musculoskeletal pain.

\section{Risk of infection and transmission of diseases and compliance with prevention regulation}

Since the outbreak of COVID-19, the demand for couriers has risen. Wolt (Keane 2020), Amazon (Palmer 2020) and Uber (Spurk and Straub 2020) took actions to expand their delivery activities. Because they are in daily contact with numerous clients and coworkers, couriers may get infected at work and spread the disease to others ("Can you catch COVID-19 from delivered packages" 2020; Nguyen and $\mathrm{Vu} 2020$ ). According to the World Health Organization (2021), there is evidence for an increased risk of transmission in occupations that require significant person-toperson contact. The perceived risk of infection and related consequences to infected people and their surroundings are expected to be related to more caution and compliance with regulation because fear causes more cautious decision-making (Tipples 2018). Also as evidenced by a meta-analysis of the safety climate literature, safety behavior is a result of the combination of management's commitment to employees' 
safety and health, the supervisor's safety role, the safety and health procedures and the individual's responsibility for health and safety (Alruqi et al. 2018).

Based on the reviewed literature, we hypothesized:

H3: factors are associated with compliance with COVID19 safety regulations.

H3a: fear of infection is positively related to couriers' compliance with regulations to prevent the spread of COVID-19.

H3b: employers' perceived efforts to care for couriers' health and perceived customers' compliance with COVID19 prevention regulations are positively related to couriers' compliance with regulations to prevent the spread of COVID-19.

Couriers' working conditions and hazards are rarely studied. The COVID-19 pandemic and the new employee-employer relationships that increased working with online "platform" raised awareness of the occupation and the need to better understand its health risks. This study explored the working conditions of couriers in Israel, the safety and health risks they encounter, and the association between them, including problems arising from their work during the COVID-19 pandemic.

\section{Methods}

\section{Procedures and participants}

An online questionnaire survey was sent to a professional survey panel company. The company has a representative panel of the Israeli population. Based on the company's assessment of the prevalence of couriers in each age group the requirement was to include panelists aged 20-30, because they comprised the main age group of couriers. The first question was a screening question that asked about their current occupation. A courier was one option of eight occupations. Only participants who indicated that they are: 1) couriers, 2) signed that they are older than 18 , and 3 ) signed their free consent for the participation, received the full questionnaire. The link was sent to about 3500 people; 2142 answered the screening question (61\% response rate), of which 237 were couriers who answered the full questionnaire. Participants were 155 men (67\%) and 82 women, aged 21-30 (one 40-years-old have passed the screening and was also included), with a mean age of 25.2.

\section{Measures}

\section{Working conditions}

Data were collected on organization type and size, mode of employment, supplied equipment and workloads defined as: weekly working hours in all jobs, length and distribution of shifts and parcel weight. All questions were close ended, and adapted from Byun et al. (2020) with relevant changes for Israeli labor laws (for example working hours).

The following terms of employment were calculated as a sum of responses to three statements: "I receive from the workplace payment for sick days," "I receive from the workplace payment for days off," and "I receive from the workplace personal accident insurance." Scores ranged from 0 (none) to 3 (all benefits).

\section{Behavioral measures of compliance with safety regulations}

Indication of careless road behavior was examined by two indicators: driving when feeling unwell and using a mobile phone while driving. The questions were adapted from Klauer et al. (2006).

Driving when feeling unwell was calculated as the average of responses to two statements asking about driving while tired and driving when feeling unwell (for example, having a headache) on a scale of 1 (never), 2 (rarely), 3 (sometimes), and 4 (often). Reliability was good $(\alpha=0.76)$. Two statements dealing with traffic violations relevant to a two-wheeled vehicle were eliminated because a two-wheeled vehicle was used by only one third of the couriers.

Smartphone use was examined via four statements that asked about the frequency of using a mobile phone for talking or reading and writing messages on a scale of 1 (never), 2 (on some deliveries), and 3 (on almost all deliveries), with good reliability $(\alpha=0.80)$. A statement that asked about using a navigation app was removed because it lowered the reliability of the index.

\section{Stress}

Stress was assessed by five statements dealing with symptoms of stress (sadness, anger, feeling stressed, difficulty sleeping, headaches) and the frequency of their occurrence in recent months on a scale from 1 (not at all) to 5 (every day). The reliability of the index was good $(\alpha=0.86)$, and total scores were calculated as an average. This measure was adapted from Goldenhar et al. (2003).

\section{Road accidents}

Two questions asked about the number of accidents in which participants had been involved in (1) during the last 3 years and (2) since the first lockdown in March 2020. Further questions dealt with consequences of the accident related to health, days off, and economics. 


\section{Musculoskeletal pains}

Musculoskeletal pains were examined by eight statements taken from a Nordic questionnaire (Kuorinka et al. 1987) dealing with the frequency of pain in the back, limbs, and joints during deliveries, with responses on a scale of 1 (not at all), 2 (once in a while), 3 (once a week) 4 (once in a shift), and 5 (several times each shift). The reliability of the index was excellent $(\alpha=0.91)$, and final scores were calculated as an average.

\section{Number of person-to-person contacts}

The number of people with whom the courier come in contact during a typical day (colleagues, customers, and suppliers) was measured on a scale of 1 (none), $2(1-10), 3$ (11-20), and 4 (more than 20). Responses were summarized into a single index that indicates the estimated number of daily meetings. The scale values range from 3 (no encounters) to 12 (more than 60 encounters). The index was built by the researchers, it was used in prior unpublished study $(n=305)$ and presented good convergent and discriminant validity.

\section{Fear of infection}

Because the new and unfamiliar situation of the pandemic this measure was built by the researchers and involved four statements dealing with the extent of the courier's fear of being infected or infecting others (family, customers, and coworkers) with COVID-19 on a scale of 1 (not at all afraid) to 5 (very afraid). The measure had high reliability $(\alpha=0.89)$, and the average was calculated. Two statements from the measure - fear of being infected and fear of infecting family members - were used in a prior study. They presented good convergent and discriminant validity (Egozi et al. 2020).

\section{Compliance with COVID-19 regulations}

This measure assessed compliance with guidelines for preventing the spread of COVID-19. The index was constructed by the researchers from five statements that asked about behaviors related to rules such as wearing masks, practicing social distancing, measuring fever, etc. All statements were answered on a scale of 1 (fully comply), 2 (partially comply), 3 (do not comply) and 4 (irrelevant). Responses of "irrelevant" were recoded as missing, and the scale was reversed $(\alpha=0.74)$. All five statements were aggregated to the minimum strictness for each statement, such that those who indicated in at least one statement that they were not compliant received a low compliance score (1), those who indicated partial compliance in at least one statement received a partial compliance score (2), and those who indicated full compliance in all statements received a full compliance score (3). The measure was used in two prior studies and presented good convergent and discriminant validity (Egozi et al. 2020).

\section{Statistical analyses}

Specific statistical tests are presented for each hypothesis test in the results section. The statistical tests were performed in SPSS 25 and R 3.6.2 with 95\% confidence intervals.

\section{Results}

\section{Descriptive data}

Regarding marital status, 55\% were single, $44 \%$ were married or in a relationship, and $1 \%$ were divorced; $78.5 \%$ had no children. Regarding education, 58\% graduated from high school, $17 \%$ had an occupational professional education (occupation certificate), and $25 \%$ were students or graduates of higher education institutions.

\section{Work conditions and job demands}

Most of the couriers (71\%) were salaried employees in an organization, $19 \%$ were working with an online platform, and $10 \%$ were self-employed. About half of the couriers $(n=131,55 \%)$ reported that deliveries were their only job, whereas $45 \%(n=106)$ were working in delivery as extra job (see Tables 1, 2). Couriers who worked more than one job worked significantly more hours a week than couriers who had one job $\left(\chi^{2}=10.26, p<0.05\right)$. The types of deliveries varied, with 53\% delivering ready-made meals and the rest delivering other items: groceries, home and office equipment, documents and letters, electronics, textiles, and miscellaneous items. Half of the participants had less than a year of experience in deliveries, and for $80 \%$, this was their
Table 1 Working hours between couriers with one or multiple jobs

\begin{tabular}{|c|c|c|c|c|c|c|c|c|c|}
\hline & \multicolumn{4}{|c|}{ Shift timing } & \multirow{2}{*}{$\begin{array}{l}\text { Longer than } \\
\text { 8-h shifts }\end{array}$} & \multicolumn{4}{|c|}{ Weekly working hours } \\
\hline & Morning & Afternoon & Night & Varies & & $<35$ & $35-42$ & $43-50$ & $>50$ \\
\hline One job & $23 \%$ & $22 \%$ & $5 \%$ & $50 \%$ & $17.6 \%$ & $43 \%$ & $36 \%$ & $15 \%$ & $6 \%$ \\
\hline Two + jobs & $16 \%$ & $21 \%$ & $6 \%$ & $57 \%$ & $12.3 \%$ & $31 \%$ & $31 \%$ & $21 \%$ & $17 \%$ \\
\hline
\end{tabular}


Table 2 Prevalence of working conditions

\begin{tabular}{ll}
\hline Variable & $\%$ \\
\hline Package weight & \\
$<10 \mathrm{~kg}$ & 77 \\
$10-25 \mathrm{~kg}$ & 19 \\
$>25 \mathrm{~kg}$ & 4 \\
Vehicle & \\
Bicycle or electric bicycle & 23 \\
Motorcycle & 21.5 \\
Car & 48.5 \\
Van & 6 \\
Other & 1 \\
Vehicle ownership & \\
Self & 61 \\
Company & 39 \\
\hline
\end{tabular}

first job as a courier. Most of the couriers (67\%) had their driving license for more than 3 years.

Of those who carried out deliveries in a vehicle they owned, 55\% did not have their fuel expenses reimbursed; for $85.5 \%$, their vehicle insurance was not covered by the company. Employment benefits (sick days, vacation days, and accident insurance) were not given to $32 \%$ of respondents; $41 \%$ received some of these benefits, and $27 \%$ received all these benefits (see Table 3).

Terms of employment were not related to the seniority of the courier for all employment types, but they were related to weekly working hours. Couriers who worked more than $35 \mathrm{~h}$ a week received more benefits, and couriers who worked less than $20 \mathrm{~h}$ a week received the fewest benefits.

\section{Road behavior}

The average score for use of a smartphone device was 1.74 $(\mathrm{SD}=0.54)$, with $60 \%$ reporting a low frequency of use and $7 \%$ reporting use during almost all deliveries. For example, $29 \%$ of couriers reported writing a message while driving during some deliveries, and $7 \%$ sent messages while driving during all deliveries.

A second measure of unsafe behavior assessed driving while tired or when feeling unwell on a 4-point scale. The reported average was $1.86(\mathrm{SD}=0.76)$, with $49 \%$ reporting very low frequency $(<2)$ and $3 \%$ reporting high frequency (>3.5).

\section{Accidents, musculoskeletal pain, and stress}

The couriers were asked about the number of accidents in which they were involved before and after March 2020 and the severity of their injuries. Thirty-one couriers (13\%) had been involved in accidents in the last 3 years, five of which happened since March 2020. Of the 31, eight reported a physical injury and five reported financial expenses due to treatment following the injury. Twenty-six reported a loss of working days and three reported a financial cost incurred due to repairs and insurance.

Many couriers $(61 \%)$ reported rarely or almost never feeling musculoskeletal pain during deliveries. The most prevalent musculoskeletal pain was lower back pain, which $22 \%$ reported suffering once or multiple times in a shift. Additionally, $37 \%$ of the couriers reported pain in their limbs or back at least once a shift; and 5\% suffered from multiple musculoskeletal pains. The prevalence of musculoskeletal pains for two-wheeled vehicle drivers compared to car drivers is presented in Table 4. Chi-square tests revealed no significant difference between the vehicles except for neck and nape pains which were more prevalent among car-driving couriers $\left(\chi^{2}=10.28, p<0.05\right)$.

Stress was measured as the mean of five symptoms on a 5 -point scale $(1=$ not at all to $5=$ every day). Mean stress was $2.45(\mathrm{SD}=0.98)$. About a third of the couriers $(38 \%)$ reported low stress $(<2)$ and $9 \%$ reported high levels of stress ( $>4$ : i.e. more than once a week). Relative to the time before the COVID-19 pandemic, 60\% said their level of stress had increased, $38 \%$ said their stress had not changed, and $2 \%$ felt their stress had decreased.

\section{Hypothesis 1 and 2 testing}

The first hypothesis was that workload is negatively related to safety behavior through the mediation of stress. Correlations between workload measures and stress were tested by a linear regression. Only shift duration $(\beta=0.19, p<0.05)$ was significantly correlated to stress; other measures of workload-weekly working hours ( $\beta=0.00$, ns), weekly working hours in deliveries $(\beta=-0.04, \mathrm{~ns})$, and package weight $(\beta=-0.02, \mathrm{~ns})$ —were not significantly correlated.
Table 3 Prevalence of employee received benefits by type of employment

\begin{tabular}{lllll}
\hline & $\begin{array}{l}\text { Salaried } \\
\text { employee }(\%)\end{array}$ & $\begin{array}{l}\text { "Platform" partial } \\
\text { employment }(\%)\end{array}$ & $\begin{array}{l}\text { Self-employed } \\
(\%)\end{array}$ & Total (\%) \\
\hline Sick days & 63 & 21 & 10 & 50 \\
Paid vacation days & 59 & 15 & 10 & 46 \\
Accident insurance coverage & 65 & 29 & 20 & 54 \\
\hline
\end{tabular}


Table 4 Prevalence of musculoskeletal pains for driving vehicle

\begin{tabular}{llllll}
\hline & Not at all (\%) & Rarely (\%) & $\begin{array}{l}\text { Once a } \\
\text { week (\%) }\end{array}$ & $\begin{array}{l}\text { Once a } \\
\text { shift }(\%)\end{array}$ & $\begin{array}{l}\text { A few } \\
\text { times a } \\
\text { shift }(\%)\end{array}$ \\
\hline Two-wheels $(n=105)$ & & & & & \\
Shoulders and upper back & 38 & 38 & 11 & 5 & 8 \\
Lower back & 35 & 40 & 8 & 8 & 9 \\
Neck and nape & 39 & 41 & 8 & 5 & 7 \\
Arms and hands & 47 & 28 & 10 & 9 & 6 \\
Legs and knees & 44 & 26 & 10 & 10 & 10 \\
Car or van $(n=130)$ & & & & & 7 \\
Shoulders and upper back & 32 & 39 & 9 & 13 & 7 \\
Lower back & 26 & 39 & 9 & 14 & 12 \\
Neck and nape & 32 & 35 & 17 & 8 & 8 \\
Arms and hands & 30 & 38 & 9 & 11 & 11 \\
Legs and knees & 33 & 35 & 12 & 10 & 10 \\
\hline
\end{tabular}

In line with Hypothesis 1a, the relationship between shift duration and driving while feeling unwell was partially mediated by stress, $F(2,234)=20.73, p<0.001$ (see coefficients in Fig. 1). The indirect effect was $0.03(0.13 \times 0.24)$. A mediation test was done using the mediation function of the MBESS library in $\mathrm{R}$ (version 3.6.2) with 5,000 bootstrapped iterations. The unstandardized indirect effect was 0.03 ( $p<0.001 ; 95 \%$ CI 0.01, 0.06). The direct effect of shift duration was still significant (coefficient $=0.11, p<0.01$ ). The indirect effect was small. Moreover, weekly working hours were not correlated with stress ( $r=0.06$, ns); thus, workload and stress were further tested separately and not as mediators related to safe driving behaviors.

Hypotheses 1 and 2 were tested in one combined model due to the role of stress as a predictor of accidents and musculoskeletal pains. The model was tested by structural equation modeling analysis in $\mathrm{R}$ (version 3.6.2). The model presented good fit indexes and significant correlations $\left(\chi^{2}=9.87, p>0.05, \chi^{2} / d f=1.23, \mathrm{CFI}=0.98, \mathrm{TLI}=0.97\right.$, RMSEA $=0.03$, SRMR $=0.03$; (see standardized coefficients in Fig. 2). The results show a relationship between unsafe behavior measured as driving while feeling unwell and road accidents $(\beta=0.24, p<0.01)$, explaining $6 \%$ of the variance in accident involvement. These results give partial support to Hypothesis 1b. Unsafe behavior measured as using a smartphone while driving was not related to higher rates of involvement in road accidents; $11 \%$ of those who almost never used a smartphone while driving were involved in road accidents, compared to $13 \%$ of those who reported using smartphone while driving $\left(\chi^{2}<1.00, \mathrm{~ns}\right)$. Unsafe behavior was linked to working longer hours in a week $(\beta=0.17$, $p<0.01)$, shift duration $(\beta=0.11, p=0.07)$, and courierreported stress $(\beta=0.32, p<0.001)$.

The second hypothesis was that stress and workload are positively related to musculoskeletal pains, and it is supported by the results. Stress had a strong correlation ( $\beta=0.44, p<0.001)$ with musculoskeletal pains, and package weights were also correlated with musculoskeletal pains $(\beta=0.18, p<0.01)$.

\section{Delivering during the COVID-19 pandemic}

Compared to the period before March 2020, 46\% of couriers indicated they worked more, $19 \%$ worked less, and $35 \%$ experienced no change during the COVID-19 pandemic. The couriers were asked about being supplied with equipment
Fig. 1 Stress partially mediates the relationship between shift duration and driving while feeling unwell

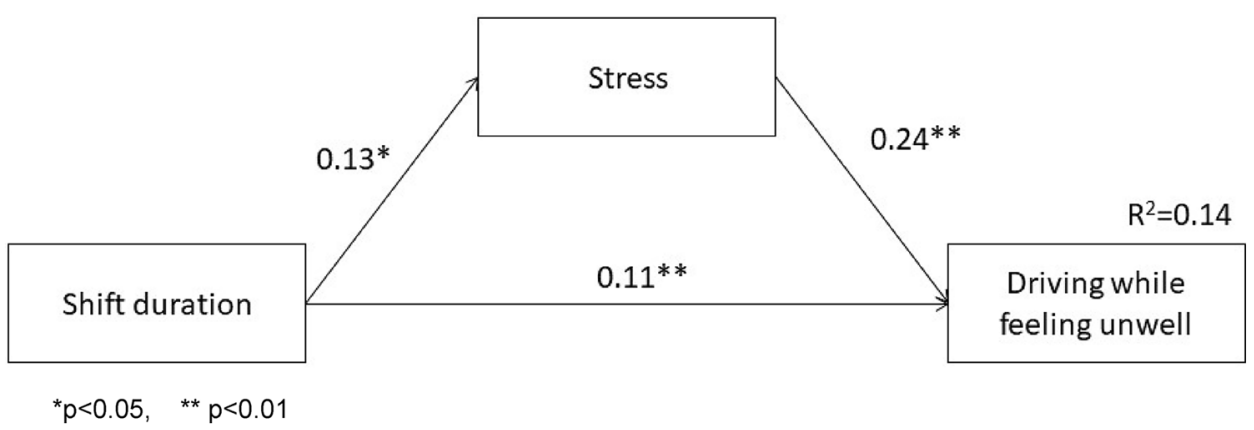


Fig. 2 Predictors of involvement in road accidents and musculoskeletal pains

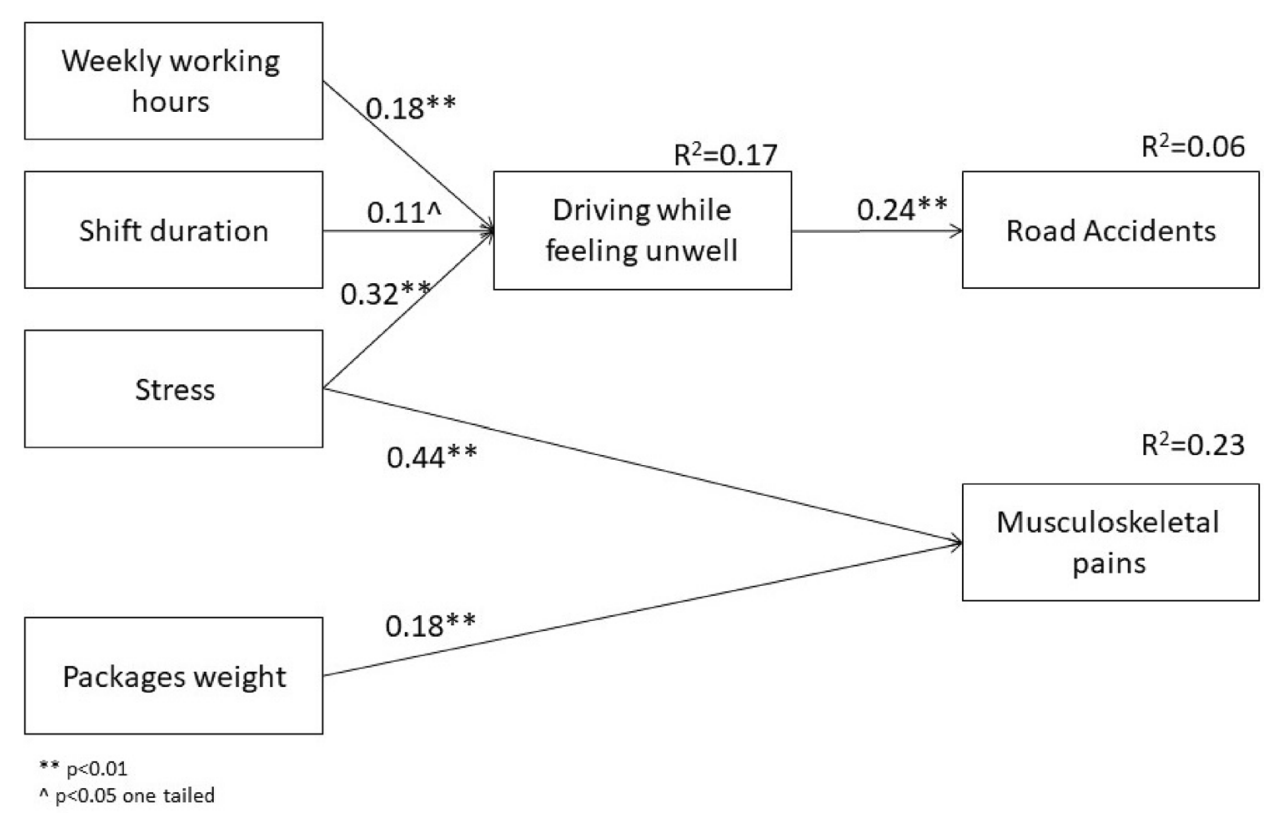

to prevent infection; for $39 \%$ of the respondents, their workplace did not provide masks or gloves, and $38 \%$ of couriers did not receive means for disinfecting their hands and surfaces. Many of the couriers (65\%) met more than 20 people during a typical workday. The couriers reported how much their customers complied with regulations to prevent infection. About a fifth (21\%) reported full compliance, $74 \%$ reported partial compliance, and 5\% reported no compliance. The couriers reported their self-compliance with these regulations: $35 \%$ reported full compliance, $38 \%$ reported partial compliance, and $27 \%$ reported no compliance. The couriers reported moderate fear of infection $(M=3.02, \mathrm{SD}=1.17$; on a 5-point scale).

\section{Hypothesis 3}

Couriers' compliance with regulations to prevent the spread of COVID-19 was related to their marital status. Couriers who were married or in romantic relationships were more apt to comply with the regulations (46.6\%) than single couriers $\left(26.2 \% ; \chi^{2}=11.36, p<0.05\right)$. Couriers with children also reported higher rates of compliance with the regulations $(51 \%)$ than couriers who were not parents $\left(31 \% ; \chi^{2}=7.05\right.$, $p<0.05)$. The third hypothesis was that couriers' compliance with COVID-19 prevention regulations is positively related to their employer's compliance, their customers' compliance, and how much they feared of being infected or infecting others with the disease. The hypothesis was tested by a linear multiple regression in SPSS 25 (see coefficients in Table 5).

The model presented in Table 5 with seven personal and organizational predictors was significant $(F(6,218)=9.85$, $p<0.001)$ and explained $21 \%$ of the explained variance in couriers' compliance with COVID-19 prevention regulations. The results partially support the hypothesis. The employers' efforts to care for the couriers' health, measured as sick days and days off, were positively related to the couriers' compliance with the regulations $(\beta=0.14, p<0.05)$.
Table 5 Factors related to couriers' compliance with COVID-19 prevention regulations

\begin{tabular}{llllll}
\hline & $b$ & $S E$ & $\beta$ & $t$ & $p^{*}$ \\
\hline Constant & 0.229 & 0.308 & & 0.744 & 0.458 \\
Age & 0.033 & 0.018 & 0.112 & 1.846 & 0.066 \\
Number of contacts during a shift & 0.035 & 0.028 & 0.078 & 1.267 & 0.206 \\
Compliance of other people with regulations & 0.372 & 0.064 & 0.359 & 5.787 & $<0.001$ \\
Employer provides COVID-19 protective equipment & 0.058 & 0.065 & 0.058 & 0.901 & 0.369 \\
Employer provides benefits (sick days, days off) & 0.094 & 0.043 & 0.140 & 2.174 & 0.031 \\
Personal fear of infection & 0.094 & 0.041 & 0.140 & 2.296 & 0.023 \\
\hline
\end{tabular}

Dependent variable: level of couriers' compliance with COVID-19 prevention regulations

*Significant for $p<0.05$ 
The employers' provision of equipment, counter to the hypothesis, was not related to the couriers' compliance with the regulations ( $\beta=0.06, \mathrm{~ns})$. The level of compliance with the regulations among other people whom couriers met during work was positively related to the couriers' compliance $(\beta=0.36, p<0.001)$. The couriers' personal fear of infecting others or being infected was positively related $(\beta=0.14$, $p<0.05$ ) to the couriers' compliance with the regulations.

\section{Discussion}

This study examined the working conditions and related safety and health risks of couriers, including risks during the COVID-19 pandemic, which increased the demand for couriers and raised their risk of infection. The results indicate that stress and work hour overload were correlated with road accidents through the mediation of unsafe road behaviors. Stress and heavy-weight loads were positively associated with musculoskeletal pains. Couriers' adherence to health regulations during the COVID-19 pandemic was positively predicted by their perceptions of customers' adherence, their fear of infection and the benefits they received from their employers.

\section{Work overload, stress, safety behavior, and accidents}

Thirteen percent of the couriers $(n=31)$ had been involved in road accidents during deliveries in the last 3 years, but only five accidents had occurred in the last 6 months. Although too small for analysis, these figures do not suggest a change in the rate of accidents during the pandemic. Two factors were found to be associated with less safe driving behavior: (a) workload measured as weekly working hours and average shift length and (b) stress. Stress, as opposed to what was hypothesized, did not mediate the relationship between workload and unsafe driving behavior. But delivering while not feeling well mediated the relationship between workload and stress increasing the risk of being involved in an accident. These findings are consistent with past research that found stress and fatigue can lead to failure to identify risk factors, poor decisions, and less safe behaviors, hence increased risk of involvement in an accident (Day et al. 2012; Smith et al. 2018).

Unsafe behaviors, such as smartphone use while driving, were not found to be related to a higher risk of being involved in an accident. This is in contrast to the research hypothesis that was based on a meta-analysis indicating risker driving behaviors while texting (Caird et al. 2014) and studies showing a higher chance of involvement in various accidents such as falls, injuries, collisions, or road accidents among young people predisposed to smartphone addiction
(Kim et al. 2017). The lack of correlation may be due to the fact that the couriers were asked about accidents in the last 3 years and road behavior in a non-overlapping period. It is possible that couriers who had an accident changed their safety behavior on the road. Also, the study by Kim and colleagues (2017) found that the risk of addiction and accidents was higher among those who used their phone for entertainment, whereas we did not examine propensity for addiction and asked only about using navigation and communication apps.

We found no significant relationship between workplace size and working conditions and involvement in road accidents. This is in contrast to findings of a study on courier work in Korea, which found an increased risk for accident during night shifts (Byun et al. 2020). However, in the Korean study, the couriers were younger, including some younger than 16 years old, some of whom did not have a driving license, used mainly two-wheeled vehicles, and worked mainly during evening and night shifts. In our study, the participants were older less than half of them used twowheeled vehicles, and only $6 \%$ always worked night shifts.

\section{Work overload, stress and musculoskeletal pains}

Another research hypothesis dealt with the relationship between working conditions and physical pain. The study focused on young couriers, most of whom had been working for a year or less and $60 \%$ of them did not or only rarely suffered from pain. Although musculoskeletal disorders increase with long-term exposure to physical work (Ervasti et al. 2019), our results suggest that even during this brief employment, stress and parcel weight were associated with musculoskeletal pains. This finding is backed up by many studies that have established a relationship between stress and pain; although the nature of the relationship is not yet fully understood - i.e., whether stress causes pain, pain causes stress, or they share a common factor such as genetics (Crofford 2015). A meta-analysis that examined the development of pain in people who reported high levels of stressors and high perceived stress in their lives did not find sufficient evidence that stress causes musculoskeletal pain (Buscemi et al. 2019). Contrary to our hypothesis, no relationship was found between the length of working hours, what hours of the day they worked, or the type of vehicle they drove and musculoskeletal pains (except pains in the neck and nape which were more prevalent among car drivers). This may be due to the relatively short trips they make. Sekkay et al. (2018) found more back pain among gas delivery workers who travel long distances compared to those who take multiple short trips. Among the couriers in our study, few made long-distance deliveries and therefore, no conclusion can be drawn as to the effect of travel range on pain. 


\section{Deliveries during the COVID-19 pandemic}

The last research hypothesis was that a relationship exists between the working conditions and the couriers' compliance with COVID-19 prevention regulations. The COVID19 pandemic has caused changes in the work of couriers and the risks they face. The changes varied-some reported an increase in workload or worsening conditions, and some noted a decrease in the volume of work. This change was related to their stress, increasing whether their workload increased or decreased compared to couriers who did not experience change. Most couriers reported an increase in their sense of stress during the COVID-19 period. The couriers' fear of infection was not found to be related to stress. However, couriers who encountered more coworkers and customers who did not comply with COVID-19 prevention rules reported higher stress. This stress may have stemmed from ancillary fears such as possible isolation or fines that would cause negative personal and economic consequences, as reported by healthcare providers who raised concerns of financial prices they might need to pay if they are infected (Kumar et al. 2020) or fear regarding the risk they pose to their communities (Taylor et al. 2020).

Married couriers and couriers with children reported greater compliance with infection prevention rules than single or childless couriers. Understandably and accordingly, the more the couriers reported fear of being infected or infecting others, the more they followed the regulations intended to prevent infection. Support for this evidence regarding the fear of getting infected or infecting family members can be found in a study with healthcare workers during the pandemic (Kumar et al. 2020). The strongest correlation was found with the perceived behaviors of others. The more the couriers reported that customers and coworkers they encountered during deliveries complied with the regulations, the more the couriers themselves complied with the regulations a result that can be explained by group norms and conformity (Packer et al. 2021).

At the organizational level, the more the employer was perceived as caring about the couriers' social and employment-related rights, the more the couriers complied with COVID-19 regulations. A content analysis of Facebook posts of Polish couriers using the Glovo app supported the importance of these benefits and health protection equipment for couriers (Polkowska 2020). It is necessary to examine working conditions and type of employment in future studies due to the minority of participants who used an online "platform" in our study.

\section{Limitations}

This preliminary research lacks comparative information for other periods without the restrictions of the pandemic, increased unemployment, and health concerns about infection at work that have characterized the pandemic. Its main limitation, however, is its focus on limited age group. This is likely why relatively few participants reported pains and accidents, making it difficult to establish valid relationships among the factors examined. Despite these limitations, the findings indicate important relationships that reinforce the need to explore this industry deeper to determine domains that need to be emphasized in occupational guidance and to protect safety and health among couriers. Further research is needed to examine a broader scope of risk factors involved in the couriers' job that were beyond the realm of this study including other classes of work accidents and exposure to air pollution

\section{Conclusions and contributions}

This study found the working conditions of couriers to be associated with their safety behavior, and their safety and health. Stress and work overload were associated with reduced safety behavior and increased risk of involvement in accidents. Stress and heavy-weight loads were associated with increased musculoskeletal pains. This study contributes to the understanding of how behavioral factors play a role at times of increased need for compliance based on the combination of organization, individual and societal factors that were correlated with the degree to which the couriers complied with COVID-19 regulations. This study is the first of its kind in Israel, and one of few around the world. The rise of various delivery and employment modes in the field highlights the importance of research on employment conditions needed to promote the safety and health of those engaged in this occupation.

\section{References}

Alruqi WM, Hallowell MR, Techera U (2018) Safety climate dimensions and their relationship to construction safety performance: a meta-analytic review. Saf Sci 109:165-173

bin Abu Hanifah MS (2015) Prevalence of musculoskeletal problems among manual handling workers in courier service industry. Int J Eng Technol Technol 4(1):81-88

Buscemi V, Chang WJ, Liston MB, McAuley JH, Schabrun SM (2019) The role of perceived stress and life stressors in the development of chronic musculoskeletal pain disorders: a systematic review. J Pain 20(10):1127-1139

Byun JH, Park MH, Jeong BY (2020) Effects of age and violations on occupational accidents among motorcyclists performing food delivery. Work 65(1):53-61

Caird JK, Johnston KA, Willness CR, Asbridge M, Steel P (2014) A meta-analysis of the effects of texting on driving. Accid Anal Prev 71:311-318

Can you catch COVID-19 from delivered packages? (2020). The straits times. https://www.straitstimes.com/asia/east-asia/can-you-catchCOVID-19-from-delivered-packages 
Canadian Center for Occupational Health and Safety (2021) OSH answers fact sheets: delivery persons-general. https://www. ccohs.ca/oshanswers/occup_workplace/delivery_persons.html

Crofford LJ (2015) Psychological aspects of chronic musculoskeletal pain. Best Pract Res Clin Rheumatol 29(1):147-155

Day AJ, Brasher K, Bridger RS (2012) Accident proneness revisited: the role of psychological stress and cognitive failure. Accid Anal Prev 49:532-535

Egozi L, Gureon S, Linn S, Tzafrir S (2020) Institutional trust in abysmal crisis situations: the COVID-19 pandemic as a case study. Study Org Human Res Q 5(2):6-15 (In Hebrew)

Elfering A, Grebner S, Ebener C (2015) Workflow interruptions, cognitive failure and near-accidents in health care. Psychol Health Med 20(2):139-147

Ervasti J, Pietiläinen O, Rahkonen O, Lahelma E, Kouvonen A, Lallukka T, Mänty M (2019) Long-term exposure to heavy physical work, disability pension due to musculoskeletal disorders and all-cause mortality: 20-year follow-up-introducing Helsinki Health Study job exposure matrix. Int Arch Occup Environ Health 92(3):337-345

Fang D, Jiang Z, Zhang M, Wang H (2015) An experimental method to study the effect of fatigue on construction workers' safety performance. Saf Sci 73:80-91

Goldenhar LM, Williams LJ, Swanson GN (2003) Modelling relationships between job stressors and injury and near-miss outcomes for construction labourers. Work Stress 17(3):218-240

Haslam RA, Bentley TA (1999) Follow-up investigations of slip, trip and fall accidents among postal delivery workers. Saf Sci 32(1):33-47

Jacobsen Cesko KS (2020) Blurring the boundaries between being an employee and self-employed: an EU competition law analysis of the employment status of Wolt couriers. Copenhagen Business School

Keane J (2020) Finland's Wolt raised $€ 100$ million to defend against the 'uncertainty' facing food delivery. Forbes. https://www.forbes. com/sites/jonathankeane/2020/05/18/finlands-wolt-raised-100million-to-defend-against-the-uncertainty-facing-food-delivery/

Kim HJ, Min JY, Kim HJ, Min KB (2017) Accident risk associated with smartphone addiction: a study on university students in Korea. J Behav Addict 6(4):699-707

Klauer SG, Dingus TA, Neale VL, Sudweeks JD, Ramsey DJ (2006) The impact of driver inattention on near-crash/crash risk: an analysis using the 100-Car Naturalistic Driving Study data.) U.S Department of Transportation. https://vtechworks.lib.vt.edu/bitst ream/handle/10919/55090/DriverInattention.pdf

Kumar J, Katto MS, Siddiqui AA, Sahito B, Ahmed B, Jamil M, Ali M (2020) Predictive factors associated with fear faced by healthcare workers during COVID-19 pandemic: a questionnaire-based study. Cureus. https://doi.org/10.7759/cureus.9741

Kuorinka I, Jonsson B, Kilbom A, Vinterberg H, Biering-Sørensen F, Andersson G, Jørgensen K (1987) Standardised Nordic questionnaires for the analysis of musculoskeletal symptoms. Appl Ergon 18(3):233-237
La Porta C, Tappe-Theodor A (2020) Differential impact of psychological and psychophysical stress on low back pain in mice. Pain 161(7):1442-1458

Nahrgang JD, Morgeson FP, Hofmann DA (2011) Safety at work: A meta-analytic investigation of the link between job demands, job resources, burnout, engagement, and safety outcomes. J Appl Psychol 96(1):71-94

Nguyen TH, Vu DC (2020) Food delivery service during social distancing: proactively preventing or potentially spreading COVID-19? Disaster Med Public Health Prep 14(3):e9-e10

Packer DJ, Ungson ND, Marsh JK (2021) Conformity and reactions to deviance in the time of COVID-19. Group Process Intergroup Relat 24(2):311-317

Palmer A (2020) Amazon to hire 100,000 more workers and give raises to current staff to deal with coronavirus demands. CNBC. https:// www.cnbc.com/2020/03/16/amazon-to-hire-100000-warehouseand-delivery-workers.html

Petitta L, Probst TM, Ghezzi V, Barbaranelli C (2019) Cognitive failures in response to emotional contagion: their effects on workplace accidents. Accid Anal Prev 125:165-173

Polkowska D (2020) Platform work during the COVID-19 pandemic: a case study of Glovo couriers in Poland. Eur Soc 23(Suppl. 1):S321-S331

Sang-Hun C (2020) Delivery workers in South Korea say they're dying of 'overwork'. The New York Times. https://www.nytimes.com/ 2020/12/15/world/asia/korea-couriers-dead-overwork.html

Sekkay F, Imbeau D, Chinniah Y, Dubé PA, de Marcellis-Warin N, Beauregard N, Trépanier M (2018) Risk factors associated with self-reported musculoskeletal pain among short and long distance industrial gas delivery truck drivers. Appl Ergon 72:69-87

Smith TD, Hughes K, DeJoy DM, Dyal MA (2018) Assessment of relationships between work stress, work-family conflict, burnout and firefighter safety behavior outcomes. Saf Sci 103:287-292

Spurk D, Straub C (2020) Flexible employment relationships and careers in times of the COVID-19 pandemic. J Vocat Behav 119:103435

Taylor S, Landry CA, Rachor GS, Paluszek MM, Asmundson GJ (2020) Fear and avoidance of healthcare workers: an important, under-recognized form of stigmatization during the COVID-19 pandemic. J Anxiety Disord 75:102289

Tipples J (2018) Caution follows fear: evidence from hierarchical drift diffusion modelling. Emotion 18(2):237-256

World Health Organization (2021) Preventing and Mitigating COVID19 at work. Policy brief, 19 May 2021. World Health Organization and International Labour Organization. https://www. who.int/publications/i/item/WHO-2019-nCoV-workplace-actio ns-policy-brief-2021-1

Publisher's Note Springer Nature remains neutral with regard to jurisdictional claims in published maps and institutional affiliations. 